\title{
Evolution of volatiles in the Phlegrean \\ Volcanic District, Italy, based on melt inclusions
}

\section{ROSARIO ESPOSITO}

Colorado College

Presenting Author: rosario.esposito@unimib.it

The active Campi Flegrei (CF) and Island of Ischia (II) volcanic fields and the volcanic Island of Procida (IP) are part of the Phlegrean Volcanic District (PVD) in southern Italy. The CF has been the focus of many recent studies attempting to investigate and model the ongoing unrest started in 2005. There is a heated debate relative to what is triggering this unrest. Owing to the volcanic risk to which many people in the area are exposed, it is important to better understand the volatile evolution of magmas associated to the PVD.

In this study, I review articles in the literature focused on understanding the volatile evolution of the PVD using the melt inclusion (MI) technique. Volatile $\left(\mathrm{H}_{2} \mathrm{O}, \mathrm{CO}_{2}, \mathrm{~S}, \mathrm{Cl}\right.$ and $\left.\mathrm{F}\right)$ compositions of melt inclusions (MI) hosted in sanidine, clinopyroxene, plagioclase and olivine are reviewed and filtered based on a new protocol proposed to select MI. The most reliable MI show that volatile compositions of mafic MI are consistent with volatile composition predicted by Rhyolite-MELTS only if volatile-saturated conditions are assumed. Isobaric crystallization in the absence of volatile saturation produces trends that are inconsistent with the mafic MI filtered data.

For more silicic reliable $\mathrm{MI}$, in addition to $\mathrm{H}_{2} \mathrm{O}-\mathrm{CO}_{2}$ systematics, there are petrographic data suggesting that the magma is volatile saturated during crystallization. For instance, certain evolved magmas at PVD as those associated to the Agnano-Monte Spina eruption show heterogeneous vapor-melt trapping. Vapor in these silicic magmas is dominated by $\mathrm{CO}_{2}$. However, phyllosilicate Raman signals were also detected suggesting the magmatic vapor phase also contained significant amount of $\mathrm{H}_{2} \mathrm{O}$. Volatile compositions of silicic MI associated to the Neapolitan Yellow Tuff (NYT; $40 \mathrm{~km}^{3}$ erupted) are consistent with those predicted by Rhyolite-MELTS only if volatile-saturate isobaric crystallization is assumed starting from mafic melts at $\sim 7.5 \mathrm{~km}$. More work is in progress as this interpretation is based only on a few reliable data from the NYT. In addition, MI hosted in sanidine and in clinopyroxene from the NYT show reheating before eruptions indicating that hotter magma recharging and triggering the eruption. 